\title{
Temporalidade e Corpo numa Proposta de Formação do Psicólogo para o Trabalho com Povos Indígenas
}

\author{
Danilo Silva Guimarães ${ }^{1}$ \\ ${ }^{1}$ Universidade de São Paulo, SP, Brasil. \\ Larissa Moreira Soares ${ }^{3}$ \\ ${ }^{3}$ Universidade de São Paulo, SP, Brasil.
}

\author{
Dario Marinho de Lima Neto ${ }^{2}$ \\ ${ }^{2}$ Universidade de São Paulo, SP, Brasil. \\ Pamela Damilano dos Santos ${ }^{4}$ \\ ${ }^{4}$ Universidade de São Paulo, SP, Brasil.
}

Thiago Schaffer Carvalho ${ }^{5}$

${ }^{5}$ Universidade de São Paulo, SP, Brasil.

\begin{abstract}
Resumo: $\mathrm{O}$ artigo aborda práticas do serviço Rede de Atenção à Pessoa Indígena - vinculado ao Departamento de Psicologia Experimental do Instituto de Psicologia da Universidade de São Paulo-, no período de 2015 a 2017, visando discutir os impactos de mudanças nos procedimentos de visitas às comunidades para a formação do psicólogo. A exposição do corpo do psicólogo em formação a contextos ritualizados segundo padrões distintos de sua cultura de origem faz emergir inquietações e angústias que caracterizam o modo de relação com a alteridade. Como ferramentas para elaboração desse modo de relação, os Guarani das comunidades visitadas nos propõem diálogos em que a prioridade é o estabelecimento de uma sintonia adequada com a sintonia do outro, preliminar à discussão e encaminhamento de projetos que abordam temas difíceis relativos a situações de vulnerabilidade psicossociais que as comunidades enfrentam.
\end{abstract}

Palavras-chave: Alteridade, Dialogicidade, Intersubjetividade, Sintonia, Mbya Guarani.

\section{Temporality and Body in Proposal for Training Psychologist in the Work with Indigenous Peoples}

\begin{abstract}
The article deals with the practices of the Amerindian Support Network - linked to the Department of Experimental Psychology of the Institute of Psychology of the University of São Paulo - in the period from 2015 to 2017, aiming at discussing the impacts of changes in procedures for visiting the communities for training psychology students. The exposure of the body of the psychologist in training to ritualized contexts from different cultural patterns, in contrast to the students' original culture, gives rise to unease and disquieting feelings that characterize the relationship with alterity. As tools for the elaboration of this mode of relation, the Guarani from the communities we visited proposed to us dialogues in which the priority was to establish an adequate attunement to the attunement of the other. This attunement is a preliminary condition to discuss and forward projects that deals with challenging issues related to situations of psychosocial vulnerabilities the focused communities face.
\end{abstract}

Keywords: Alterity, Dialogicity, Intersubjectivity, Attunement, Mbya Guarani. 


\title{
Temporalidad y Cuerpo en una Propuesta de Formación del Psicólogo para el Trabajo con Pueblos Indígenas
}

\begin{abstract}
Resumen: El artículo aborda prácticas del servicio Red de Atención a la Persona Indígena - vinculado al Departamento de Psicología Experimental del Instituto de Psicología de la Universidad de São Paulo - en el período de 2015 a 2017, con el objetivo de discutir los impactos de cambios en los procedimientos de visitas a las comunidades para la formación del psicólogo. La exposición del cuerpo del psicólogo en formación a contextos ritualizados según patrones distintos de su cultura de origen hace emerger inquietudes y angustias que caracterizan el modo de relación con la alteridad. Como guías de elaboración de este modo de relación, los guaraníes de las comunidades visitadas nos proponen diálogos en los que la prioridad es el establecimiento de una sintonía adecuada con la sintonía del otro, preliminar a la discusión y encaminamiento de proyectos que abordan temas difíciles relativos a situaciones de vulnerabilidad psicosociales que las comunidades enfrentan.
\end{abstract}

Palabras clave: Alteridad, Dialogicidad, Intersubjetividad, Sintonía, Mbya Guaraní.

\section{Introdução}

O objetivo desse artigo é discutir aspectos dos procedimentos de atuação do serviço Rede de Atenção à Pessoa Indígena (Instituto de Psicologia da Universidade de São Paulo, Departamento de Psicologia Experimental - IPUSP-PSE) que alteraram qualitativamente o vínculo entre os estudantes e as pessoas das comunidades visitadas, com as quais buscamos efetivar ações e projetos em coautoria. Focalizaremos, prioritariamente, informações contidas em relatos e relatórios desenvolvidos pelos estudantes no período de dois anos a partir de julho de 2015. Destacamos, do conjunto de informações, os impactos dos deslocamentos e das vivências nas comunidades que se fizeram sentir nos corpos: desconfortos, mas também possibilidades de elaboração de experiências que consideramos enriquecedoras para a formação do psicólogo pelos motivos que serão expostos ao longo do texto.

Antes de avançarmos, cabe explicitar, com maior detalhamento, que a Rede de Atenção à Pessoa Indígena (daqui por diante usaremos apenas Rede Indígena) é, atualmente, um serviço psicológico universitário que tem como objetivo contribuir para o campo de referências que concerne a atenção às vulnerabilidades psicossociais enfrentadas por pessoas e comunidades indígenas, apoiando-se em uma constante reflexão acerca dos horizontes de possibilidades e modos de ação da Psicologia nas situações interétnicas. A Rede Indígena foi lançada como um projeto no ano de 2012, quando realizamos diversas visitas às comunidades Mbya Guarani localizadas no extremo sul da cidade de São Paulo (distrito de Parelheiros)—Tekoa Krukutu e Tekoa Tenondé Porã - e às comunidades localizadas aos pés do Pico do Jaraguá, na zona norte da cidade - Tekoa Ytu e Tekoa Pyau. Nessas visitas priorizamos rodas de conversa sobre temas que emergiam em nossa escuta das falas de lideranças comunitárias.

Adotamos um método hermenêutico para construção de conhecimento, segundo o qual a equipe que executava as atividades de extensão elaborava um roteiro semiestruturado, em reuniões de supervisão na Universidade de São Paulo (USP), das ações a serem realizadas nas comunidades que demandavam atendimento. As visitas às comunidades, por sua vez, provocavam rupturas nas preconcepções que tínhamos antes de encontrá-los. As vivências dessas experiências de ruptura, por parte da equipe, eram significativamente tomadas como objeto nas reuniões de supervisão, que se seguiam às visitas às comunidades. A própria equipe tomava o relato de seus integrantes para o desdobramento de questões teóricas e metodológicas da Psicologia nas fronteiras interculturais e interétnicas.

Nos primeiros anos da Rede, as visitas eram periódicas, quase semanais. Os estudantes ficavam algumas horas nas comunidades dialogando e encaminhando ações junto com as lideranças comunitárias. Desde 2015 a participação dos estudantes pas- 
sou a ser mais intensa na comunidade Tekoa Tangara Mirim (Itanhaém/SP) e depois incluímos o Tekoa Yyrexãkã (distrito de Marsilac, São Paulo/SP). Essas comunidades situam-se em regiões distantes da Universidade, de modo que, para chegarmos no local, demoramos cerca de 3 a 4 horas de viagem. Desse modo, tornou-se inviável que as visitas fossem feitas semanalmente, como aquelas que fazíamos às comunidades mais próximas. Inicialmente, buscamos assegurar nossa presença a cada 15 dias, alternando a participação docente e a de diferentes estudantes que realizavam estágio na Rede Indígena. No ano de 2016, contudo, fomos surpreendidos com convites de lideranças do Tekoa Tangara Mirim para que participássemos do primeiro Ka'a'i Nhemongarai ${ }^{1}$ que aconteceria naquela comunidade. O evento teve duração de três dias (de sexta a domingo). No Tekoa Ytu (bairro do Jaraguá, São Paulo/SP) fomos convidados a colaborar com as lideranças na organização do evento Xeramõi Mbaraete ${ }^{2}$, que durou dois dias, de sábado a domingo. Nessas duas ocasiões, a equipe da Rede Indígena foi convidada a dormir na comunidade no período dos eventos, o que sinalizou o aprofundamento da confiança mútua que buscávamos, entre as comunidades e nossa equipe.

As experiências de 2016 nos levaram a promover uma mudança na forma como estávamos estabelecendo as aproximações com as comunidades. Ao invés de encontros frequentes e curtos, passamos a realizar encontros mais duradouros, ainda que menos frequentes. Outra ação, em 2016, que envolveu a hospedagem de estudantes no Tekoa Yyrexãkã, fazia parte do projeto de Intercâmbio de Saberes, em que lideranças do Tekoa Tangara Mirim levaram o conhecimento sobre a produção de banheiros ecológicos que, por sua vez, haviam adquirido num trabalho preliminar da Rede Indígena em parceria com o Projeto Piloto da Escola Politécnica da Universidade de São Paulo. Já no primeiro semestre de 2017, de março a julho, realizamos cinco visitas com pernoite a essas comunidades, três no Yyrexãkã e duas no Tangara Mirim. Essa mudança no procedimento será o objeto de nossas reflexões nesse artigo, a partir da Psicologia Cultural Dialógica e de aproximações com o Perspectivismo Ameríndio em Antropologia quanto à noção de corpo. Os relatos, tomados aqui para discussão, foram produzidos pelos próprios coautores desse texto, no contexto de uma atividade de extensão universitária, para fins de formação acadêmica, não se tratou, portanto, de material construído objetivando realização de pesquisa científica.

\section{A Psicologia Cultural Dialógica no contexto da Rede Indígena}

O trabalho da Rede Indígena (IPUSP-PSE) baseia-se em princípios da Psicologia Cultural em sua vertente semiótico-construtivista (Simão, 2010) com o enfoque em questões teórico-metodológicas que nos permitam compreender e intervir adequadamente como psicólogos que atuam em fronteiras interétnicas em conjunto com pessoas e comunidades indígenas.

Notamos que o estudo da cultura está presente na Psicologia desde quando essa área do conhecimento emergiu como ciência moderna nas universidades europeias e norte-americanas. Observamos a centralidade da cultura na obra de Wundt sobre o que chamou de Psicologia dos povos; nos estudos de etologia humana que visavam as relações entre o indivíduo e seu ambiente social e material; nas leituras de Freud sobre as diversas culturas e povos e em sua articulação de reflexões presentes nos textos de sociologia e antropologia à teoria psicanalítica; nas tentativas de generalização das hipóteses sobre o desenvolvimento cognitivo elaboradas por Piaget; nas tentativas de Vygotsky de tornar evidente a relevância dos aspectos socioculturais na estruturação da linguagem e do pensamento humano; dentre tantas outras possíveis referências a autores clássicos da Psicologia.

Por um lado, versões clássicas de Psicologia, como não poderiam ser diferentes, trabalhavam com ideias de seu tempo e lugar a respeito do que era etnocentricamente entendido como sociedades e culturas mais ou menos desenvolvidas, de modo que concepções e valores produzidos nos centros de poder econômico hierarquizavam as culturas e sociedades e ditavam os rumos da Psicologia e das sociedades latino-americanas. Por outro lado, a Psicologia cultural contemporânea, em sua vertente semiótico-construtivista, apresenta concepções que criticam e apontam a necessidade de revisão de

\footnotetext{
${ }^{1}$ Ritual Mbya Guarani realizado com a erva-mate.

${ }^{2}$ Evento que contou com apoio da Pró-Reitoria de Cultura e Extensão da USP e visava aproximar jovens lideranças da sabedoria tradicional dos anciãos.
} 
concepções eurocêntricas nos projetos de Psicologia em geral.

Valsiner (2007), por exemplo, discute problemas teórico-metodológicos decorrentes da pressuposição de homogeneidade qualitativa e estabilidade temporal das culturas e seus participantes, que não abarcam a natureza processual dos grupos e das pessoas. Por outro lado, Boesch (2007), discute ao menos sete mazelas das abordagens transculturais em Psicologia. As primeiras seis mazelas dizem respeito a pressupostos teórico-metodológicos equivocados dessas abordagens: tomar a cultura como variável independente; supor plausível a representatividade de amostras comparativas entre culturas; supor equivalência de significados dos instrumentos de medida nas diferentes culturas; não incluir as idiossincrasias pessoais dos investigadores como parte da investigação; o fato de as especificidades dos problemas de pesquisa ou intervenção atenderem a demandas da cultura do psicólogo e a suposição de que as informações oferecidas pelos participantes se encaixam de maneira confortável com as informações requeridas pelo psicólogo. A última mazela discutida por Boesch (2007) tem um caráter fortemente ético, enfatizando que o estudo - e acrescentamos que também a intervenção psicológica - sobre grupos culturais diversos não deveria acontecer como se as pessoas focalizadas fossem apenas fonte de informações para um interesse supostamente bem-intencionado do psicólogo. Ou seja, os participantes da pesquisa e da intervenção psicológica são ativos no diálogo em que se dá a construção de conhecimento e devem ser respeitados como coparticipantes ativos ou coautores de um trabalho que prioriza seus pontos de vista.

O diálogo com um interlocutor ativo passa, necessariamente, pela disponibilidade para se viver a inquietante experiência ${ }^{3}$ (Simão, 2015) de se relacionar com a alteridade. Demanda o desenvolvimento da capacidade de suportar a angústia decorrente do fato de que as experiências nem sempre se encaixam plenamente nas teorias das quais partimos para fundamentar qualquer conhecimento do outro. Figuei- redo (1996) aponta que o dogmatismo e o ecletismo teórico-metodológico são defesas contra a angústia e bloqueiam o acesso do psicólogo àquilo que excede sua compreensão inicial dos fenômenos:

[...] quem se agarra aos sistemas como tábua de salvação não só não pode ouvir as interpelações que viriam de outras vozes teóricas (que ficam de antemão desqualificadas), mas também não se permite ouvir o que sua prática tem a dizer, salvo na medida em que se encaixe no esquema que o psicólogo pensa que sabe. Eu não estou aqui defendendo uma posição ingenuamente empirista; sei muito bem que as teorias são indispensáveis para que se torne inteligível o campo das experiências; são elas que nos ajudam na tarefa de configuração desse campo e sem elas estaríamos desamparados diante de uma proliferação de acontecimentos completamente fora do nosso manejo. Contudo, o reconhecimento desse papel para as teorias e, mais amplamente, 0 reconhecimento de que não há experiência sem pressupostos não se pode confundir com o aforamento dogmático a um conjunto de crenças que resulte na própria impossibilitação de qualquer experiência nova (pp. 18-19).

A vertente semiótico-construtivista da Psicologia Cultural considera que a prática do diálogo, abarcando pensamentos, sentimentos, expectativas, imaginações e desejos se efetua no tempo irreversível das relações interpessoais. Cada pessoa canaliza os impactos da situação dialógica, organizando as experiências já vividas e guiando possibilidades de se viver novas experiências (Valsiner, 1998), que geram expectativas sob a constante espreita do imponderável caos (Boesch, 2002). Desconstruções, reconstruções e ajustes em face daquilo que passamos a ponderar a cada nova experiência constituem o ciclo da ação produtora de novidades na cultura, envolve tensão na negociação de perspectivas internas à heterogeneidade da cultura da qual participamos, de forma transforma-

\footnotetext{
${ }^{3}$ Uma noção de experiência inquietante foi proposta por Simão (2015):

"Experiências inquietantes fazem emergir zonas amorfas de significado e situações ambíguas para o self. Elas pertencem à ordem fenomenológica dos sentimentos concernindo experiências subjetivas que tocam a pessoa afetiva e pré-reflexivamente. Como tal, elas são vividas em primeira pessoa. Experiências inquietantes criam instabilidade, tensão, perturbam ou mesmo ferem as expectativas da pessoa sobre sua 'habilidade-de-entender' a si mesmo e às suas relações Eu-Outro-Mundo, instigando a pessoa a sentir, pensar e agir de modo cognitivo e afetivo, em diferentes direções daquelas que ela estava seguindo até então; de tal modo que a pessoa pode chegar a integrar sentimentos despertados por ela em sua base afetivo-cognitiva, que, por sua vez, irá também mudar" (p. 7).
} 
tiva, situados em distintas posições. As transformações na cultura, que cada pessoa promove desde uma posição específica, por sua vez, reorganizam a qualidade do todo em alguma intensidade.

As elaborações das experiências pessoais, afetivo-cognitivas, estão imbricadas nas narrativas das experiências vividas, que, por sua vez, se articulam às narrativas disponíveis na cultura. As pessoas comparam suas experiências às experiências dos outros, e assim avaliam suas próprias intenções e as intenções das pessoas que participam de seu campo cultural. Os ajustes entre processos recursivos na fronteira entre imaginação e percepção da pessoa podem se coordenar ou produzir ruídos em sua relação com os demais processos recursivos que compõem a dinâmica intrapessoal das outras pessoas e mundos culturalmente significados. Os ajustes recíprocos se interpelam produzindo transformações em cada pessoa-mundo que interage, deslocando as estabilizações semióticas previamente elaboradas: "O ajuste recíproco de perspectivas é alcançado por uma 'sintonia com a sintonia do outro' pelo qual o estado de coisas é apresentado em um foco conjunto de atenção, fazendo sentido de, e falado sobre a partir de uma posição temporária adotada por ambos os participantes na comunicação" (Rommetveit, 1992, p. 20).

A busca pela entrada em sintonia com a sintonia do outro, por sua vez, nos orienta para uma dimensão do fenômeno psicológico que está para além do conteúdo dos discursos, enfatizando a importância das dimensões sensíveis das relações que envolvem outros sentidos apreendidos pelo corpo, como o ritmo das trocas entre si mesmo e o outro no tempo irreversível, que viabiliza a construção de uma temporalidade compartilhada (Guimarães, 2015). A temporalidade que abordamos aqui diz respeito à reciprocidade de atividades, nas quais "a pessoa, ao realizar suas tarefas, também atende a outras pessoas" (Ingold, 2000, p. 196). Consideramos que atividades das pessoas são coordenadas com certa periodicidade em diferentes esferas da vida. Por exemplo, na vida cotidiana de certas famílias existem padrões de encontros entre seus membros, regulados pelos horários das refeições (café da manhã, almoço e jantar). Na cultura acadêmica, há regulações que definem períodos de aulas, de avaliações, coordenação da produção acadêmica, elabora- ção de projetos, execução e desenvolvimento de relatórios etc. Essas regulações estão articuladas a certos momentos do dia - da semana, meses e anos - em que as atividades são realizadas.

Já nas culturas indígenas, por exemplo, entre os Mbya Guarani com os quais desenvolvemos as ações da Rede Indígena, notamos que outra temporalidade está em jogo e em relação a ela a equipe da Rede Indígena viveu experiências inquietantes no período de trabalho que aqui tomamos para análise.

\section{O diálogo com o perspectivismo ameríndio: temporalidade e corpo}

Tomando o desafio da construção de diálogos interétnicos, partimos da reflexão de que se estrangeiros visitam uma cultura distinta, deparam-se num primeiro momento com uma zona de ruído, uma diferença de ritmos entre as culturas que pode ser entendida como um dos elementos que levam à percepção de um choque-cultural (Wagner, 1981), porque o ritmo do estrangeiro não está sintonizado com o ritmo daqueles que visita.

Todavia, para o estrangeiro chegar, e estar na comunidade de forma a trocar efetivamente experiências em sintonia com as pessoas que visita em sua viagem, é necessário se adequar, tranquilizar a respiração, observar e perceber o outro, o próprio da cultura local e assim, entrar no ritmo da comunidade para possível posterior ação conjunta: são, portanto, demandados procedimentos de sintonização rítmica para se lidar com a alteridade, para amenizar os ruídos, e de fato poder construir um diálogo. Esses procedimentos podem demorar horas, dias, muitas vezes "nada acontece" porque os ritmos não encontraram a sintonia necessária (Guimarães, \& $\mathrm{Nash}^{4}$ ).

Assumimos que a regulação recursiva rítmica é uma propriedade dos sistemas orgânicos subpessoais, que incluem a coordenação dos momentos de vigília e de sono, fome, sede e sua satisfação etc. Todas essas demandas recursivas para os sistemas sub-pessoais e para as tarefas sociais necessitam de uma harmonização rítmica da relação do organ-

${ }^{4}$ Guimarães, D. S. \& Nash, R. (em preparação). O que nos comunica o ritmo? Reflexões a partir do construtivismo semiótico-cultural em psicologia. 
ismo/pessoa com outros organismos/pessoas em seu entorno. Contudo, o domínio das interações não está confinado aos movimentos dos seres humanos (Ingold, 2000, p. 199).

Nossa percepção da passagem do tempo está conectada à nossa percepção da paisagem como um todo, ou seja, por exemplo, nossa atenção pode estar sintonizada com a das plantas e animais além das pessoas e mais: "os ritmos das atividades humanas ressoam não apenas com outros seres viventes mas também com um todo que abriga outros fenômenos rítmicos—os ciclos do dia e da noite e das estações do ano, os ventos, as marés e assim por diante" (Ingold, 2000, p. 200).

Como aprofundaremos a seguir, o relato dos estudantes da Rede Indígena contrasta a temporalidade vivida no contexto urbano/acadêmico e a temporalidade experimentada nas aldeias como algo que deixa marcas no corpo, seja no cansaço do corpo que se desloca para regiões distantes, seja na exposição do corpo a práticas culturais muito distintas daquelas às quais se está habituado: cantos, danças, sons, cheiros etc. Contudo, é por meio da exposição do corpo a essas práticas que pensamos ser viável chegar a alguma sintonia com a sintonia do outro, condição para que o diálogo, no sentido dialógico aqui proposto, aconteça. Ao tocarmos na questão do corpo esclarecemos, com Viveiros de Castro (1996), que:

O que estou chamando de "corpo", portanto, não é sinônimo de fisiologia distintiva ou de morfologia fixa; é um conjunto de afecções ou modos de ser que constituem um habitus. Entre a subjetividade formal das almas e a materialidade substancial dos organismos, há um plano intermediário que é o corpo como feixe de afecções e capacidades, e que é a origem das perspectivas ${ }^{5}$ (p. 128).

A noção de habitus, por sua vez, remonta à epistemologia ecológica de Bordieu (1983), que rompe com a dicotomia entre realidade exterior e realidade psíquica, ao enfatizar o contínuo e recíproco diálogo entre interioridade e exterioridade. Desse modo, as intervenções sobre o corpo propostas pelos indígenas nas aldeias e a disponibilidade dos corpos das pessoas da equipe que se dispõem a visitar um ambiente sociocultural específico passam a ser correguladas. A reciprocidade na atenção dos corpos em relação é guiada para a produção conjunta de modos de relação humanizados com o outro, superando os afetos que possam levar a bloqueio das possibilidades de continuidade da relação. Por exemplo, medo ou agressividade, que são sentimentos presentes no imaginário que a cultura brasileira - e mesmo latino-americana tem sobre o indígena, difundido em estereótipos historicamente reproduzidos desde os primeiros exploradores das Américas, nos ambientes religiosos, nas escolas e na produção científica (Jahoda, 1999).

A partir do exposto nessa introdução é possível concluir que a Rede Indígena tem se debruçado sobre processo de formação de psicólogos para o diálogo com diversas culturas, promovendo condições para que o profissional em formação possa lidar com as angústias decorrentes da exposição de seus corpos a experiências inquietantes que desregram concepções e práticas amplamente difundidas na formação básica em Psicologia - com suas teorias clássicas de um tempo e lugar em que o indígena não ocupava a posição de sujeito. Ao fazê-lo, temos, necessariamente, que refletir com os indígenas sobre concepções e práticas que estão no escopo da Psicologia, ainda que conceitualmente pensadas e propostas segundo modelos de compreensão que são próprios das culturas com as quais lidamos. Ao mesmo tempo, valorizamos diálogos interdisciplinares com concepções e práticas similares em seus focos e propósitos, presentes nas diferentes ciências humanas.

\section{0 relato dos estudantes traz implicações da organização das atividades da Rede Indígena conciliada com procedimentos Mbya Guarani}

Passamos, agora, para uma discussão a partir de relatos que estudantes da Rede Indígena produziram sobre suas visitas às comunidades. Buscaremos evidenciar, nos relatos, as tensões vivenciadas pelos

\footnotetext{
${ }^{5}$ Para o Perspectivismo Ameríndio:

“Todo ser a que se atribui um ponto de vista será então sujeito, espírito; ou melhor, ali onde estiver o ponto de vista, também estará a posição de sujeito. Enquanto nossa cosmologia construcionista pode ser resumida na fórmula saussureana: o ponto de vista cria o objeto - o sujeito sendo a condição originária fixa de onde emana o ponto de vista -, o perspectivismo ameríndio procede segundo o princípio de que o ponto de vista cria o sujeito; será sujeito quem se encontrar ativado ou 'agenciado' pelo ponto de vista" (Castro, 1996, pp. 372-373).
} 
estudantes na relação com a alteridade indígena e a elaboração afetiva empreendida na tentativa de entrar em sintonia com a sintonia do outro. Na exposição dos relatos, omitimos os nomes pessoais e as comunidades envolvidas, porque o que nos interessa é compreender a elaboração que o psicólogo em formação faz de sua experiência. Antes de trazer os relatos para análise, passamos à descrição de alguns procedimentos gerais de trabalho da equipe.

As atividades da equipe da Rede Indígena são acompanhadas por supervisão docente com periodicidade semanal no período letivo. Na supervisão, são discutidas as referências teórico-metodológicas que fundamentam o nosso trabalho, por meio de leitura e discussão de textos. Fazemos, ainda, o planejamento das visitas às comunidades e de outras ações da equipe, realizamos a avaliação das visitas e demais ações. As datas das visitas às comunidades são sempre agendadas com antecedência com as lideranças locais e com parceiros indígenas de aldeias situadas em São Paulo, que nos acompanham. Em 2016, quando ainda não fazíamos o pernoite nas comunidades, docente e estudantes saíam da Universidade por volta de 6 h30 da manhã, chegando nas comunidades cerca de 11 horas. Lá éramos recebidos pelas lideranças, almoçávamos e iniciávamos as conversas. O retorno era programado para 15h30. Após as visitas, os estudantes produziam relatos para discussão coletiva em supervisão.

A seguir, apresentamos o excerto de um dos relatos do Estudante 1, que nos acompanhou nessas visitas:

Estudante 01 (excerto de relato da visita do dia 17/03/2016): Ao chegarmos à aldeia, nos concentramos em um local diferente dos outros encontros. Fiquei surpreendido com a quantidade de pessoas que estavam se organizando em uma roda para a conversa, em sua grande maioria eram jovens. [o cacique da aldeia] nos pediu para cumprimentá-los um por um. Após o cumprimento individual, [o cacique] nos explicou que a presença dos jovens se dava devido ao fato de que havia o interesse dos mais velhos de transmitirem qual a realidade indígena no Brasil e [para] que possam adquirir autonomia para que no futuro sejam capazes de se tornarem líderes dentro e fora da Tekoa. [...] Após a nossa apresentação, foi a vez dos jovens Guarani de se apresentarem, falaram seus nomes em Guarani e em português, sua idade [...]. Percebi os jovens muito tímidos, porém interessados em todo aquele evento [...] após a apresentação de cada indígena ali presente, [o cacique] começou a falar como as condições na aldeia estavam péssimas [...] e planejava levar algum documento escrito [à Funai'] [...] Nos dispomos a ajudar e [...] começamos a redigir um esboço de uma carta ali mesmo. Era muito interessante notar, que ao longo da redação, ia surgindo mais e mais pessoas, cada uma lembrando de algum problema específico, tornando explícito o sentimento coletivo dos Guarani de incômodo com a situação que a [...] aldeia deles se encontra. Por fim, a ideia inicial [do que fora previamente planejado pela equipe da Rede Indígena antes da viagem] tornou-se ideia secundária [...].

O relato do Estudante 1 revela que a equipe tinha a expectativa de executar o que havia planejado nas reuniões de supervisão e se via surpreendida com a situação configurada pelos indígenas para recebê-la. Na discussão das vivências, os estudantes notaram, em muitos momentos, que as lideranças indígenas dirigiam as conversas para campos que se desviavam do foco de projetos ou ações específicas, mesmo do previamente acordado em reuniões anteriores. Com o tempo, foi ficando compreensível para a equipe que a comunidade buscava estabelecer vínculos sob outras bases e que certos acordos temporários não eram, necessariamente, prioridades. Em outros relatos de visitas encaminhados pelos estudantes aparecem algumas propostas de ação tomadas, inicialmente, como inusitadas ou cindidas do trabalho a ser feito: jogar futebol, nadar no rio, dançar fora ou dentro da casa de reza, conhecer os lugares da terra indígena por meio de caminhadas, ações que, algumas vezes, se mostravam mais importantes para os indígenas do que algumas conversas sobre quais projetos iriam ou poderiam ser realizados. Por um lado, como a equipe ficava poucas horas na aldeia, muitas vezes tínhamos a impressão que o trabalho estava sendo pouco efetivo. O desvio do que era previamente planejado e acordado nos apontava para uma reflexão

\footnotetext{
${ }^{6}$ Fundação Nacional do Índio, órgão indigenista oficial do Estado Brasileiro.
} 
sobre a temporalidade, a necessidade de construção de uma sintonia entre os ritmos de trabalho da comunidade e dos universitários.

Após algumas experiências de pernoite em aldeias em 2016, no primeiro semestre de 2017, passamos a estruturar as visitas de acordo com o seguinte roteiro: Saindo por volta de 13 horas da Universidade, com a chegada na comunidade prevista para 17 horas, continuamos sendo recebidos pelas lideranças da comunidade. Deixamos nossa bagagem no Opy, casa de reza ou de reuniões da comunidade, e participamos do japyxaka, momento de manifestação pública das lideranças, demais pessoas da comunidade e visitantes. Nesse momento também são previstas avaliações das demandas prioritárias da comunidade, deliberações e planejamento de ações, para encaminhamento no dia seguinte. Finalmente, fazemos um jantar coletivo e preparamos o local para o descanso durante a noite em barracas de campinglevadas pelos visitantes. Na manhã do dia seguinte, fazemos um café da manhã coletivo e, posteriormente, são realizadas ações conjuntas: rodas de conversa, oficinas, registro de informações, preparação de documentos, relatórios, publicações, edição de registros audiovisuais e demais materiais definidos nas etapas preliminares. No período da tarde, após o almoço, nos despedimos e retornamos à cidade de origem.

A seguir, apresentamos o excerto do relato de uma estudante que participou de uma das visitas com pernoite:

Estudante 2 (excerto de relato da visita do dia 26/05/2017 com retorno no dia seguinte): Chegamos na Tekoa na noite do dia 26 , ficamos um tempo na casa de reza, onde os homens fumaram o petyngua [cachimbo], todos nós visitantes no apresentamos e combinamos com o [cacique] de debater os nossos projetos em comum no dia seguinte. Depois jantamos na casa do cacique [...] e ficamos em volta da fogueira ouvindo histórias dos Guarani, dentre elas, várias continham animais e a relação predatória dos seres da natureza e as visões de cada um acerca da religiosidade Guarani, importantíssima para essa população, segundo eles. [...] No dia seguinte, depois do café da manhã, fomos para a casa de reza para conversar sobre as ações da rede e as propostas de cada um.
O relato aponta para uma forma recorrente das comunidades visitadas lidarem com as tarefas e as ações da equipe: há uma ênfase muito grande na introdução dos visitantes em práticas culturais que orientam o processo de sintonização dos envolvidos, adequando nossos corpos para a escuta qualificada de questões difíceis a serem tratadas posteriormente. Cabe notar que com a possibilidade do pernoite, temas não diretamente relacionados ao foco das ações e projetos previamente planejados puderam emergir sem uma preocupação maior com o quanto estávamos produzindo com o tempo que tínhamos. Os corpos estavam mais disponíveis para a experiência e para trocas com o outro não dirigidas.

Embora, em certas ocasiões, os assuntos tratados pudessem ser agradáveis e para os participantes do diálogo, o formato de diálogo proposto nas comunidades, em especial no japyxaka que acontece no início da noite, por vezes, faz emergir nos estudantes afetos intensos e de difícil elaboração, como no caso do relato a seguir:

Estudante 3 (relato sobre conjunto de visitas realizadas em 2016): As idas às aldeias e o constante diálogo a respeito da história dos povos indígenas no Brasil me fizeram questionar quais seriam as minhas próprias origens. Sou branco, filho de baianos, que vieram para a cidade de São Paulo, mas nossa árvore genealógica para na Bahia e em indícios de uma ancestralidade europeia, que se confunde entre espanhola e portuguesa. Nos povos originários, é como se eles carregassem a natureza e a matéria dentro de si, e pisam sobre onde nasceram, se reconhecem como cor da própria terra. Eu, filho de migrantes netos de imigrantes, me sinto uma pessoa carregada de "estrangeireidades", sendo um estrangeiro na própria cidade e um de uma outra forma nas aldeias. Entrar em contato novamente com a alteridade me faz rememorar essa angústia que não tem lugar definido nem respostas fáceis, o que inclusive me fez fazer um discurso emocionado em uma das visitas em que pernoitei. Haviam nos convidado para falar na frente e fui um dos primeiros de nosso grupo. Eu estava engasgado e contagiado com a fala do professor [...] que falou primeiro. Ele contava de sua conexão com os Maxakali e das motivações de seu trabalho. Talvez eu tenha me reconhecido neles ou 
talvez eu não quisesse mais me reconhecer neles. Me reconheci novamente como estrangeiro e isso gerou angústias.

Por um lado, ser branco, quando se está na aldeia, é ter o corpo do antepassado opressor, faz lembrar que se tem a mesma origem dos ancestrais que invadiram e exploraram, no passado, mas também no presente, as terras e comunidades indígenas de modo violento e abusivo. Por outro lado, ao ser tratado pelos indígenas como um parceiro ou aliado - por exemplo, ser alimentado, conversar descontraidamente sobre histórias pessoais, mitos, brincar, contar piadas, cantar, dançar, ser autorizado a pernoitar na aldeia etc. - nos permite, ainda que momentaneamente, experimentar a reversão de imagens desumanizadas de um e de outro às quais fomos habituados. Ou seja, as experiências vividas nos encontros promovidos pela Rede Indígena atualizam o encontro entre brancos e indígenas de forma distinta da realidade desastrosa que conhecemos ao longo da história. O procedimento das visitas desconstrói e reconstrói, circunstancialmente em nosso escopo de trabalho, a relação e os corpos (enquanto feixes de afecções) para que possam aparecer mais humanizados uns para os outros.

Vemos acontecer, também, uma Psicologia reversa. O processo de subjetivação dos visitantes é problematizado demandando reflexões, por vezes, profundas sobre si mesmo, seu lugar na história e no mundo contemporâneo. Quando disponível, o corpo chamado à frente no espaço público é observado e transformado. As angústias decorrentes desse processo são elaboradas com o tempo e com o apoio da equipe nas supervisões que acontecem na universidade.

\footnotetext{
Estudante 4 (excerto de relato da visita do dia 07/07/2017 com retorno à universidade no dia seguinte): Chegamos na aldeia e já havia escurecido. Possivelmente eu estava cansada da viagem. Carregamos nossas coisas até a casa de reza. Quando chegamos na casa de reza, uma mudança ainda mais radical do ambiente surgiu para mim. O cheiro de defumação, o aspecto visual da fumaça que preenchia toda a casa de reza e tornava os feixes de luz mais visíveis, a música e os cantos em uma língua que eu não conheço nada, mas, mesmo assim, o som reverberava em mim.
}

Todos esses aspectos criavam um ambiente que rompiam completamente com meu dia-a-dia. Me senti invadida por aquele ambiente, os cheiros, a fumaça, o som, a reverberação física do som no meu corpo, tudo isso me atravessou e me paralisou. Me acalmou. Eu não entendia nada do que se passava na casa de rezas, fiquei pensando que parecia algum ritual de cura, não soube ao certo, mas fiquei observando e gostando muito de sentir aquela calma, aquela desaceleração do meu corpo, quase em uma meditação induzida não pelo silêncio, mas pelo excesso de estímulos (cheiro, som, tato). Notei que algumas conversas começaram a surgir entre o grupo [equipe da Rede Indígena] e algumas lideranças Guarani. Fiquei um pouco atenta à conversa, mas logo percebi que não queria participar da conversa e até mesmo prestar atenção nela. Mas eu sabia que era para isso que eu estava ali, e eu precisava me inteirar mais dos assuntos, pois era minha primeira visita. Fiz um esforço e me aproximei para participar da conversa, mas não estava disposta, então só escutei, não tive vontade de falar e nem saberia o que falar. Em algum momento o cacique interrompeu a conversa dizendo que estava muito envolvido com o trabalho ritual que estava acontecendo às minhas costas e que achava melhor deixar essa conversa para o dia seguinte. Não posso negar que isso me trouxe grande alívio, pois não sentia disposição física ou mental para engajar uma conversa de tamanha importância. Voltei novamente minha atenção ao ritual, dancei com as mulheres e me senti muito bem, apesar de não saber exatamente o porquê ou o significado da dança que eu estava participando. Meu corpo falou mais alto, já que eu estava em um ambiente em que tudo era novo, em que eu não tinha conhecimento de quase nada. Surpreendentemente, no dia seguinte, tivemos uma conversa muito profunda e com falas muito inspiradas, demonstrando uma certa ideia de que cada coisa parece ter seu tempo certo de acontecer.

Este relato sintetiza diversos aspectos do que vimos discutindo desde a introdução do artigo. Num dado momento nos vemos diante dos limites do discurso verbal para a imersão e compreensão de processos culturais. Vivenciar certas experiências ritua- 
lizadas com o outro afeta significativamente o corpo e permite o alinhamento de pontos de vista. Dessa forma, para que haja trocas significativas e possamos compartilhar um "chão comum" com os indígenas, nos parece ser exigido ao psicólogo uma abertura a experiências não previstas em teorias e práticas típicas da formação do psicólogo. Das visitas da Rede Indígena às comunidades Guarani, no relato dos estudantes emerge um sentimento ambíguo diante da alteridade, o desejo de aproximar-se junto com um certo receio, ao entrar em contato com aquilo que excede preconcepções (Gadamer, 2008) de cada participante do encontro.

\section{Considerações finais}

Este artigo refletiu sobre processos de formação de psicólogos para o diálogo com diversas culturas. Buscamos promover condições para que o profissional em formação possa lidar com angústias decorrentes da exposição de seus corpos a experiências inquietantes que desregram concepções e práticas amplamente difundidas na formação. Tais concepções e práticas predominam em teorias clássicas de um tempo e lugar em que o indígena não ocupava a posição de sujeito.

Parte do trabalho da equipe da Rede de Atenção à Pessoa Indígena consiste em propiciar um cenário para elaboração de práticas de atenção às vulnerabilidades psicossociais enfrentadas por pessoas e comunidades indígenas, apoiando-se em uma constante reflexão acerca dos horizontes de possibilidades e modos de ação da Psicologia nas situações interétnicas.

Observamos que as visitas às comunidades indígenas fizeram emergir, na equipe, um sentimento ambíguo em relação ao encontro com o outro: o desejo de se aproximar, mas com receio de entrar em contato com aquilo que excede preconcepções de cada participante (choque-cultural). A vivência de experiências ritualizadas com o outro, por um lado, afetou significativamente o corpo e permitiu o alinhamento de pontos de vista: indicando limites do discurso puramente verbal para a imersão e compreensão de processos culturais. A equipe e os membros da comunidade indígena, por outro lado, foram ativos no diálogo em que se deu a construção de conhecimento e coautores de um trabalho que articulou seus pontos de vista como parte de tradições culturais distintas.

O relato dos estudantes contrasta a temporalidade vivida no contexto urbano/acadêmico e a temporalidade experimentada nas aldeias como algo que deixa marcas no corpo, seja no cansaço do corpo que se desloca para regiões distantes, seja na exposição do corpo a práticas culturais muito distintas daquelas às quais se está habituado: cantos, danças, sons, cheiros etc. Contudo, é por meio da exposição do corpo a essas práticas que pensamos ser viável encontrar uma sintonia na relação, condição para que o diálogo, no sentido dialógico, aconteça.

\section{Referências}

Boesch, E. E. (2002). The myth of lurking chaos. In: H. Keller, Y. H. Poortinga, \& A. Schölmerich (Eds.), Between culture and biology: Perspectives on ontogenetic development (pp. 116-135). Cambridge: Cambridge University.

Boesch, E. E. (2007). The seven flaws of cross-cultural psychology: The story of a conversion. In: W. J. Lonner, \& S. A. Hayes, Discovering cultural psychology: A profile and selected readings of Ernest E. Boesch (pp. 247-258). Charlotte, NC: Information Age.

Bourdieu, P. (1983). Questões de sociologia. Rio de Janeiro, RJ: Marco Zero.

Castro, E. B. V. (1996). Os pronomes cosmológicos e o perspectivismo ameríndio. Mana, 2(2), 115-144. https://doi. org/10.1590/S0104-93131996000200005

Figueiredo, L. C. M. (1996). Revisitando as psicologias: Da epistemologia à ética das práticas e discursos psicológicos. São Paulo, SP: Vozes.

Gadamer, H. -G. (2008). Verdade e método I: Traços fundamentais de uma hermenêutica filosófica. São Paulo, SP: Vozes. (Trabalho original publicado em 1960).

Guimarães, D. S. (2015). Temporality in cultural trajectories: A psychological approach on semiotic constructions. In: L. M. Simão, D. S. Guimarães, \& J. Valsiner (Orgs.), Temporality: Culture in the flow of human experience (pp. 331-358). Charlotte, NC: Information Age. 
Ingold, T. (2000). The perception of the environment: Essays on livelihood, dwelling and skill. New York, NY: Routledge Jahoda, G. (1999). The images of savages: Ancient roots of modern prejudice in western culture. New York, NY: Routledge.

Rommetveit, R. (1992). Outlines of a dialogically based socio-cognitive approach to human cognition and communication. In: A. H. Wold (Ed.), The dialogical alternative: Towards a theory of language and mind (pp. 19-44). Oslo: Scandinavian University.

Simão, L. M. (2010). Ensaios dialógicos: Compartilhamento e diferença nas relações eu outro. São Paulo, SP: Hucitec.

Simão, L. M. (2015). The contemporary perspective of semiotic cultural constructivism: For an hermeneutical reflexivity in psychology. In: G. Ruggieri, R. A. Marsico, \& S. Salvatore (Eds.), Reflexivity and psychology (pp. 65-85). Charlotte, NC: Information Age.

Valsiner, J. (1998). The guided mind: A sociogenetic approach to personality. Cambridge, MA: Harvard University.

Valsiner, J. (2007). Culture in minds and societies: Foundations of cultural psychology. New Delhi: Sage.

Wagner, R. (1981). The invention of culture. Chicago, IL: University of Chicago.

\section{Danilo Silva Guimarães}

Professor do Instituto de Psicologia da Universidade de São Paulo (IP-USP), São Paulo - SP. Brasil. Doutor pelo IP-USP.

(iD) https://orcid.org/0000-0002-0583-2979

E-mail:danilosg@usp.br

Dario Marinho de Lima Neto

Graduando do Instituto de Psicologia da Universidade de São Paulo (IP-USP), São Paulo - SP. Brasil. https://orcid.org/0000-0001-5144-0944

E-mail: dario.marinho.neto@usp.br

\section{Larissa Moreira Soares}

Graduanda do Instituto de Psicologia da Universidade de São Paulo (IP-USP), São Paulo - SP. Brasil.

(iD) https://orcid.org/0000-0001-7806-1063

E-mail: larissa.soares@usp.br

\section{Pamela Damilano dos Santos}

Graduanda do Instituto de Psicologia da Universidade de São Paulo (IP-USP), São Paulo - SP. Brasil.

(iD) https://orcid.org/0000-0001-9646-9847

E-mail: pamela.d.dos.santos@gmail.com

\section{Thiago Schaffer Carvalho}

Graduando do Instituto de Psicologia da Universidade de São Paulo (IP-USP), São Paulo - SP. Brasil.

E-mail: thiago.schaffer.carvalho@usp.br

Endereço para envio de correspondência:

Av. Prof. Mello Moraes, 1721, CEP 05508-030. Cidade Universitária - São Paulo - SP

Recebido 28/03/2019

Aceito 06/05/2019

Received 03/28/2019

Approved 05/06/2019 
Psicologia: Ciência e Profissão 2019 v. 39 (n.spe), e221929, 147-158.

Recibido 28/03/2019

Aceptado 06/05/2019

Como citar: Guimarães, D. S., Lima Neto, D. M., Soares, L. M., Santos, P. D., \& Carvalho, T. S. (2019). Temporalidade e corpo numa proposta de formação do psicólogo para o trabalho com povos indígenas. Psicologia: Ciência e Profissão, 39(n.spe), 147-158. https:// doi.org/10.1590/1982-3703003221929

How to cite: Guimarães, D. S., Lima Neto, D. M., Soares, L. M., Santos, P. D., \& Carvalho, T. S. (2019). Temporality and body in proposal for training psychologist in the work with indigenous peoples. Psicologia: Ciência e Profissão, 39(n.spe), 147-158. https:// doi.org/10.1590/1982-3703003221929

Cómo citar: Guimarães, D. S., Lima Neto, D. M., Soares, L. M., Santos, P. D., \& Carvalho, T. S. (2019). Temporalidad y cuerpo en una propuesta de formación del psicólogo para el trabajo com pueblos indígenas. Psicologia: Ciência e Profissão, 39(n.spe), 147-158. https://doi.org/10.1590/1982-3703003221929 